\title{
Manufacturing Feasibility and Forming Properties of Cu-4Sn in Selective Laser Melting
}

\author{
Zhongfa Mao ${ }^{1}$, David Z. Zhang ${ }^{1,2, *}$, Peitang Wei ${ }^{1}$ and Kaifei Zhang ${ }^{1}$ \\ 1 State Key Laboratory on Mechanical Transmission, Chongqing University, Chongqing 400044, China; \\ zhongfamao@cqu.edu.cn (Z.M.); peitangwei@cqu.edu.cn (P.W.); kaifeizhang@cqu.edu.cn (K.Z.) \\ 2 College of Engineering, Mathematics and Physical Sciences, University of Exeter, North Park Road, \\ Exeter EX4 4QF, UK \\ * Correspondence: zhangzw@cqu.edu.cn; Tel.: +86-23-6510-2537
}

Academic Editor: Guillermo Requena

Received: 27 February 2017; Accepted: 15 March 2017; Published: 24 March 2017

\begin{abstract}
Copper alloys, combined with selective laser melting (SLM) technology, have attracted increasing attention in aerospace engineering, automobile, and medical fields. However, there are some difficulties in SLM forming owing to low laser absorption and excellent thermal conductivity. It is, therefore, necessary to explore a copper alloy in SLM. In this research, manufacturing feasibility and forming properties of $\mathrm{Cu}-4 \mathrm{Sn}$ in SLM were investigated through a systematic experimental approach. Single-track experiments were used to narrow down processing parameter windows. A Greco-Latin square design with orthogonal parameter arrays was employed to control forming qualities of specimens. Analysis of variance was applied to establish statistical relationships, which described the effects of different processing parameters (i.e., laser power, scanning speed, and hatch space) on relative density (RD) and Vickers hardness of specimens. It was found that $\mathrm{Cu}-4 \mathrm{Sn}$ specimens were successfully manufactured by SLM for the first time and both its RD and Vickers hardness were mainly determined by the laser power. The maximum value of RD exceeded $93 \%$ theoretical density and the maximum value of Vickers hardness reached $118 \mathrm{HV} 0.3 / 5$. The best tensile strength of 316-320 MPa is inferior to that of pressure-processed $\mathrm{Cu}-4 \mathrm{Sn}$ and can be improved further by reducing defects.
\end{abstract}

Keywords: selective laser melting; additive manufacturing; copper alloy; relative density; Vickers hardness

\section{Introduction}

Selective laser melting (SLM) is a unique additive manufacturing (AM) technology that enables us to produce dense metal parts by means of layer-by-layer construction using metal powders based on CAD models [1-3]. In comparison with traditional manufacturing methods, SLM offers a wide range of advantages. It can directly manufacture highly complex parts that are difficult or unable to be fabricated by conventional methods, with mechanical properties comparable to those of wrought materials. It does not require expensive tooling and machining in manufacturing and, therefore, saves manufacturing costs and lead-time [4,5]. It is also a favorable method for the fabrication of functionally-graded multi-material parts [6]. Furthermore, SLM technology offers high degrees of freedom for designers throughout the product development, from conceptual design to low-volume trial production [7]. These advantages make SLM a very useful method for the fabrication of biocompatible implants, conformal cooling channels of heat exchangers, light-weight structures in biomedicine, molds, the aerospace industry, and other fields [2,8]. However, current studies on SLM are limited and mainly focus on steel and iron-based alloys, titanium and its alloys, and Inconel 
and nickel-based alloys [2]. Copper alloys have recently appeared as a new type of potential material for SLM.

Copper alloys, compared with other metal alloys, exhibit moderate mechanical properties, high corrosion resistance, excellent electrical and thermal conductivity, as well as outstanding machinability and formability [9]. As such, these alloys are widely used in electronics, machinery, aerospace, defense, and other industrial fields, such as heat exchangers for various types of equipment, high-precision springs and bearings, electronic connectors, plastic deformation tools, and propulsion devices in marine applications $[10,11]$. However, fabrication methods of copper alloys are limited in conventional powder metallurgy technology, cold compaction, sintering, and infiltration. These methods are not appropriate for manufacturing parts with intricate shapes. Therefore, a large number of valuable studies were reported about copper alloys in direct metal laser sintering (DLMS), including balling phenomenon, densification mechanisms, and microstructural characteristics during the sintering process [12,13]. Meanwhile, the combination of design flexibility, excellent process capabilities, and the fully dense mechanism offered by SLM makes SLM a very attractive potential method for creating copper alloy components. It was reported that thin-wall $\mathrm{W}$-Cu alloy components could be directly manufactured by SLM and influences of different energy input on the thickness of single-track walls were previously analyzed [14]. The research on Cu-10Sn bronze for SLM showed that its yield and ultimate strengths were much higher than those attained by casting and were accompanied by a significant improvement in ductility [11]. Moreover, multi-materials including copper alloy, such as 316L stainless steel and C18400, AlSi10Mg and C18400, were explored by SLM and the interfacial character was fully analyzed $[15,16]$. Cu-Cr-Zr-Ti alloy specimens were also fabricated by SLM and their microstructure and mechanical properties were investigated and compared to hot-rolled samples [17].

There are quite a few difficulties in manufacturing copper alloy parts in SLM. The high thermal conductivity and reflectivity of copper alloys at the laser result in significant heat loss and inadequate melting of powder [16]. A systematic experimental process to effectively identify appropriate SLM processing parameters for copper alloys is minimally discussed in the literature. Therefore, in order to explore the manufacturing process of copper alloys in SLM, in this work the influences of SLM processing parameters on forming properties of $\mathrm{Cu}-4 \mathrm{Sn}$ are investigated using experimental methods. The $\mathrm{Cu}-4 \mathrm{Sn}$ bronze was selected for further investigation of microstructure and mechanical properties in SLM because it has the minimum casting shrinkage coefficient among non-ferrous metals and has relatively slight dendrite segregation among tin-copper alloys, as the segregation depends on the level of tin.

\section{Materials and Methods}

\subsection{Experimental Materials}

The feedstock material used for this investigation was gas-atomized $\mathrm{Cu}-4 \mathrm{Sn}$ powder produced by SNDVARY (Wuxi SNDVARY New Powder Materials Technology Co., Ltd., Wuxi, China) and its nominal chemical composition ( $\mathrm{wt} \%$ ) was: $\mathrm{Cu}=$ balance, $\mathrm{Sn}=3.95 \%$, impurities $=0.2 \%$, maximum. The morphology of the powder was observed using scanning electron microscopy VEGA2 (TESCAN, Brno, Czech Republic). The raw powder is almost spherical with minor satellites, as shown in Figure 1a. Particle size distribution was measured using a laser particle size analyzer BT-9300Z (Bettersize Instruments Ltd., Dandong, China). The result in Figure 1b shows an essential log-normal distribution with particle sizes of $11.66 \mu \mathrm{m}$ (D10), $31.81 \mu \mathrm{m}$ (D50), and $63.36 \mu \mathrm{m}$ (D90). 

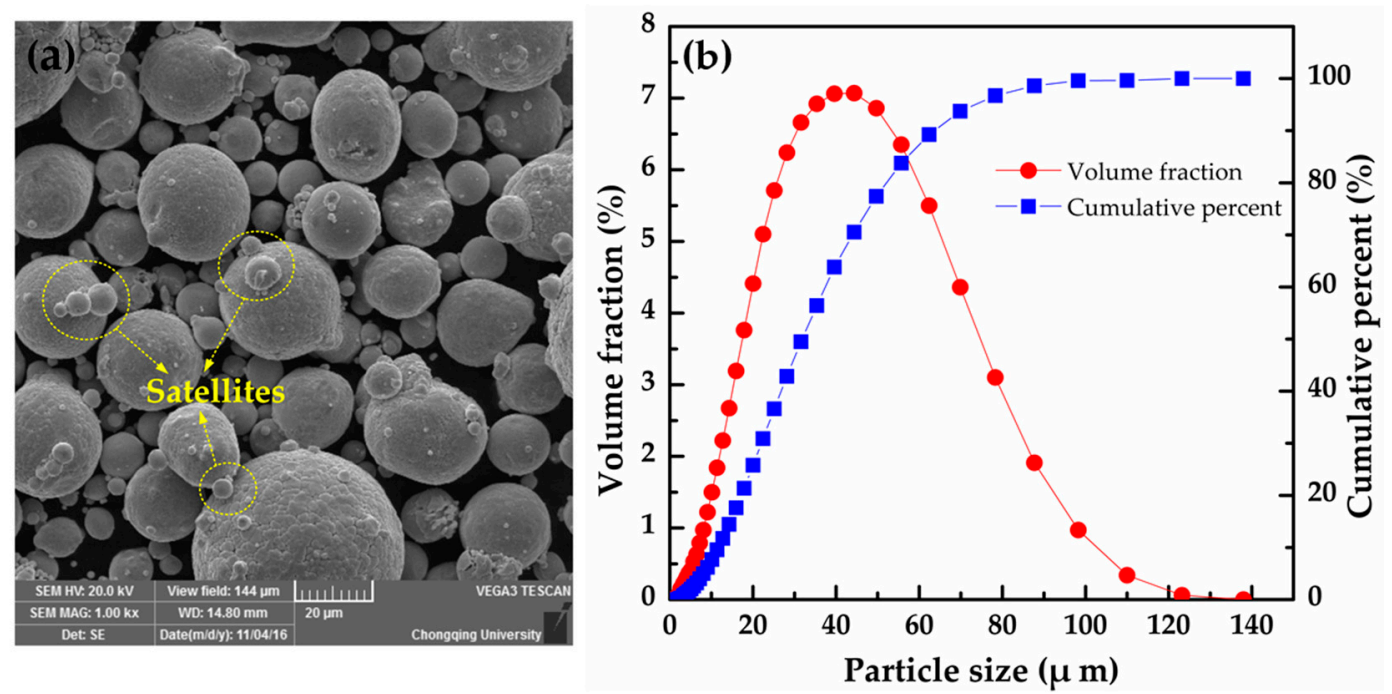

Figure 1. (a) SEM morphology and (b) particle size distribution of the Cu-4Sn powder.

\subsection{Experimental Equipment}

Experiments were performed on the commercial SLM machine EOSINT M280 (EOS GmbH, Krailling, Germany). The source of radiation is a single-mode continuous wave ytterbium fiber laser YLR-200 (IPG Photonics, Oxford, MS, USA) operating at a wavelength of $1.07 \mu \mathrm{m}$ and producing a laser beam with an energy intensity distribution with a Gaussian profile. The main characteristics of this machine are as follows: the maximum laser power is $195 \mathrm{~W}$; the maximum laser scanning speed is $7 \mathrm{~m} / \mathrm{s}$ and the laser spot size on the surface of the powder bed is $100 \mu \mathrm{m}$. The process chamber provides a closed environment filled by inert gas, such as nitrogen or argon, and the substrate temperature can be chosen according to different materials.

\subsection{Experimental Methods}

First, single-track experiments with different combinations of processing parameters were conducted to preliminarily narrow down selection windows during the exploration stage. Some key factors were considered as variables and the others were fixed in the experiment. The linear energy density (LED), defined by the ratio of laser power (LP) and scanning speed (SS), is a key factor in SLM $[18,19]$. The processing parameters used for the single-track experiments are summarized in Table 1. In order to minimize the effect of oxygen content on single tracks, it was not until the oxygen content was less than $0.1 \%$ that the argon supply to the chamber was stopped. Geometrical morphologies of single-tracks were surveyed by a Digital Microscope VHX-1000 series (Keyence, Osaka, Japan).

Table 1. SLM processing parameters used for single-track experiment.

\begin{tabular}{ccc}
\hline Parameters & Value & Increment \\
\hline LED & $100-1000 \mathrm{~J} / \mathrm{m}$ & $100 \mathrm{~J} / \mathrm{m}$ \\
LP & $50-195 \mathrm{~W}$ & $25 \mathrm{~W}$ \\
SS & $0.05-1.95 \mathrm{~m} / \mathrm{s}$ & - \\
Layer thickness & $20 \mu \mathrm{m}$ & - \\
Preheating temperature & $80^{\circ} \mathrm{C}$ & - \\
Substrate material & Die Steel (MS1) & - \\
Atmosphere & Argon (Oxygen level $<0.1 \%)$ & - \\
\hline
\end{tabular}

Based on single-track experiments, a Greco-Latin square design experiment was performed for the fabrication of the $\mathrm{Cu}-4 \mathrm{Sn}$ bulk specimens with dimensions of $5 \mathrm{~mm} \times 5 \mathrm{~mm} \times 5 \mathrm{~mm}$. In this experiment, 
the major processing parameters would be further redefined. The LP varied from 100 to $195 \mathrm{~W}$ with a step of $25 \mathrm{~W}$; the SS varied from 100 to $300 \mathrm{~mm} / \mathrm{s}$ with a step of $50 \mathrm{~mm} / \mathrm{s}$; and the hatch space (HS) varied from 100 to $180 \mu \mathrm{m}$ with a step of $20 \mu \mathrm{m}$. The scanning stripe width was fixed at $3 \mathrm{~mm}$ and other parameters were kept the same as in the single-track experiment. The cross-hatching scanning strategy was employed whereby parallel alternative scan vectors were overlaid at an angle of $67^{\circ}$ to the previous deposited layer, as shown in Figure 2. This scanning strategy has been proven to be an effective method of improving the surface roughness and reducing defects in SLM [20]. Densities of as-built specimens were measured by an electronic balance using the Archimedes method. Relative density (RD) is presented as a percentage of measured density and theoretical density $\left(8.92 \mathrm{~g} / \mathrm{cm}^{3}\right)$. Vickers hardness was measured on polished cross-sections of each specimen using a hardness tester NH-5L (Shanghai EVERONE Precision Instruments Co., Ltd., Shanghai, China) with a $300 \mathrm{~g}$ load for $5 \mathrm{~s}$. For each condition, all specimens were measured at least 10 times and results averaged after eliminating false data, so as to avoid the measuring deviation.

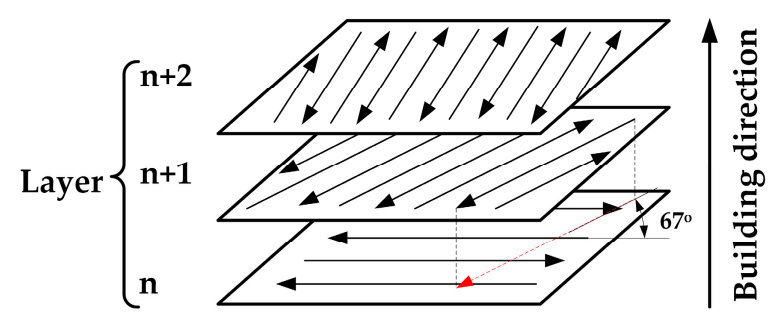

Figure 2. Scanning strategy used in SLM experiments.

According to the optimal processing parametric set in the Greco-Latin square design experiment, tensile specimens were fabricated and the configuration followed the Chinese GB/T228.1-2010 standard, as shown in Figure 3. Tensile strengths of these specimens were evaluated using an electronic universal tester CMT5105 (MTS, Eden Prairie, MN, USA) and fracture faces were examined by scanning electron microscopy VEGA2 (TESCAN, Brno, Czech Republic). Simultaneously, the chemical compositions were characterized by the energy dispersive spectroscopy (EDS) technique.

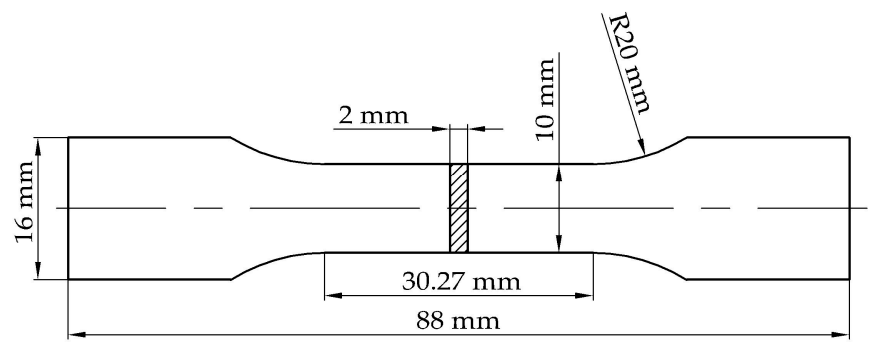

Figure 3. Configuration of tensile specimens.

\section{Results and Discussion}

\subsection{Single-Track Experiments}

Figure 4 shows morphologies of single-tracks produced by SLM on the MS1 substrate during single-track experiments. The horizontal coordinate represents LED with the values (decreasing from $1400,1100,800$, to $500 \mathrm{~J} / \mathrm{m}$ ) and the vertical coordinate represents LP with the values (increasing from 100, 150, to $195 \mathrm{~W}$ ). It can be seen from Figure 4 that solidified single-tracks present different characteristics under different processing conditions. For the same LP, the widths of single tracks decrease as the LED decreases (i.e., a decrease as the SS increases). Irregularities and distortions are 
observed when the LED decreases to $500 \mathrm{~J} / \mathrm{m}$, as illustrated in the inset (LED is $500 \mathrm{~J} / \mathrm{m}, \mathrm{LP}$ is $100 \mathrm{~W}$ ) of Figure 4. This phenomenon can be explained by the fact that the less laser energy irradiated on the powders, the narrower the heat-affected zone, which can even give rise to incomplete melting of powdery material. A similar phenomenon was previously reported [21]. For the same LED in Figure 4, a smoother and more uniform surface morphology can be seen with the increase of the LP, as shown in the inset (LED is $1400 \mathrm{~J} / \mathrm{m}, \mathrm{LP}$ is $195 \mathrm{~W}$ ). It is emphasized that the surface roughness has worsened in both low LP and high LED, such as the single track (LED is $1400 \mathrm{~J} / \mathrm{m}, \mathrm{LP}$ is $100 \mathrm{~W}$ ), which can be attributed to the unstable molten pool where a strong Marangoni flow was formed in virtue of the decreasing SS. Based on the single-track experiments, a rough processing parameter window, high LP, and large LED can be acquired.

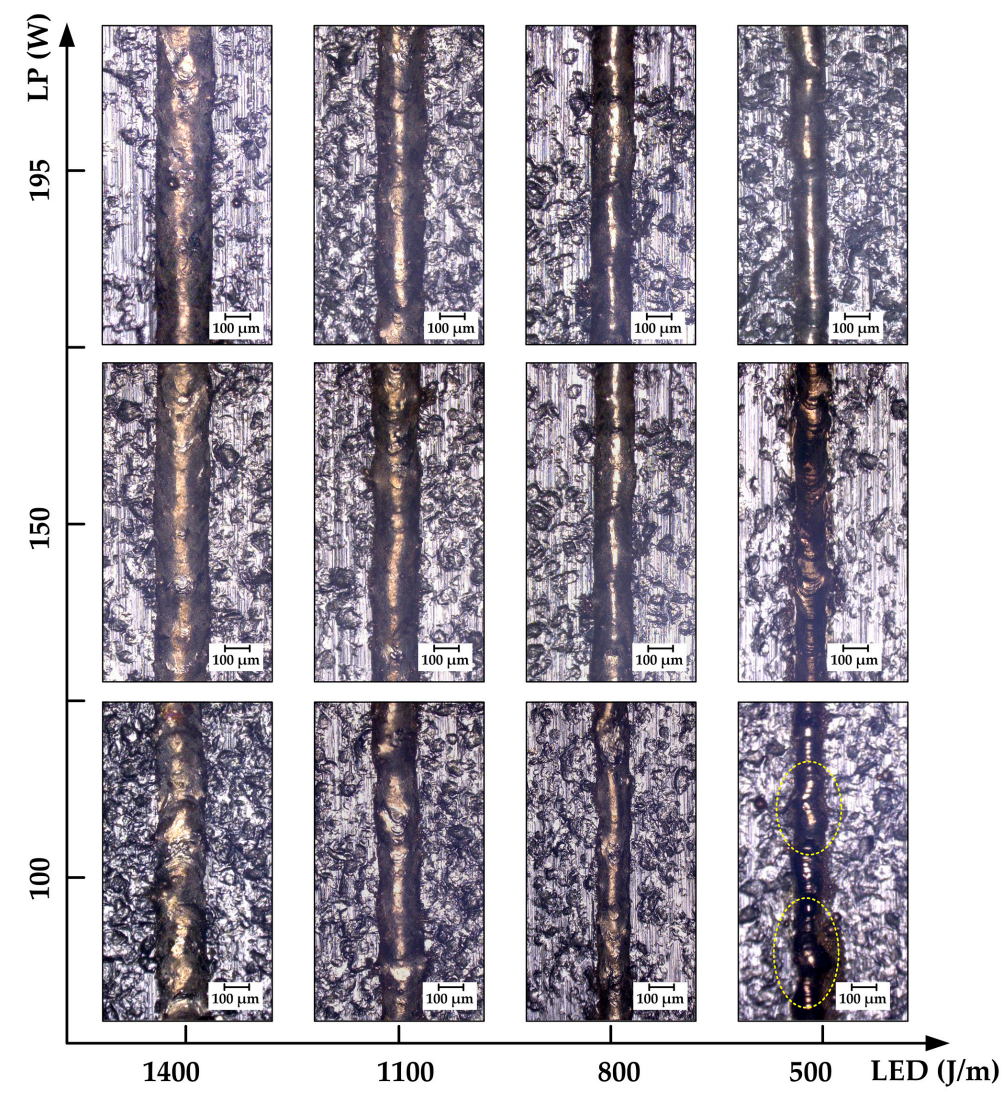

Figure 4. The morphologies of single tracks with different processing parameters.

\subsection{The Experiment of Greco-Latin Square Design}

Figure 5 shows the surface appearances of solidified $\mathrm{Cu}-4 \mathrm{Sn}$ single-layers and the corresponding bulk specimens, respectively. Thanks to the Greco-Latin square design used in this study, the number of experiments is effectively reduced without influencing the analysis of experimental results. The experimental orthogonal array is given in Table 2. The fabricated layers and specimens are distributed in the regular sequence whereby LP decreases along the $y$-axis, SS increases along the $\mathrm{x}$-axis and HS arranges according to the orthogonal method.

Figure 5 a reveals that qualities of single layers are significantly affected by different processing parameters. The LP, the energy intensity of the direct heat source, greatly determines the degree of melting of the present powder layer and re-melting depth of the previous layer. It shows a trend in Figure 5a that incomplete melting becomes more evident with the decrease of LP. The SS, characterizing the interactive time between the laser beam and powdery material, has a slight influence on the qualities 
of the single-layer. The HS represents the overlapping level of the previous track and the present track, which influences the joint strength between two adjacent single-tracks. Some black particles (i.e., incompletely melted powders) can be seen when the HS is wider than the width of a single-track, as shown in the case in Figure 5a whereby HS $=180 \mu \mathrm{m}, \mathrm{LP}=150 \mathrm{~W}$ and SS $=200 \mathrm{~mm} / \mathrm{s}$. However, final properties of specimens produced by SLM depend strongly on the interaction of various parameters rather than the influence of a single factor, which can be validated hereinafter through RD values of these specimens in Figure 5b. Here, it is worth noting that the difference in surface color of the specimens between Figure $5 \mathrm{a}, \mathrm{b}$ is due to different photographing environmental conditions.

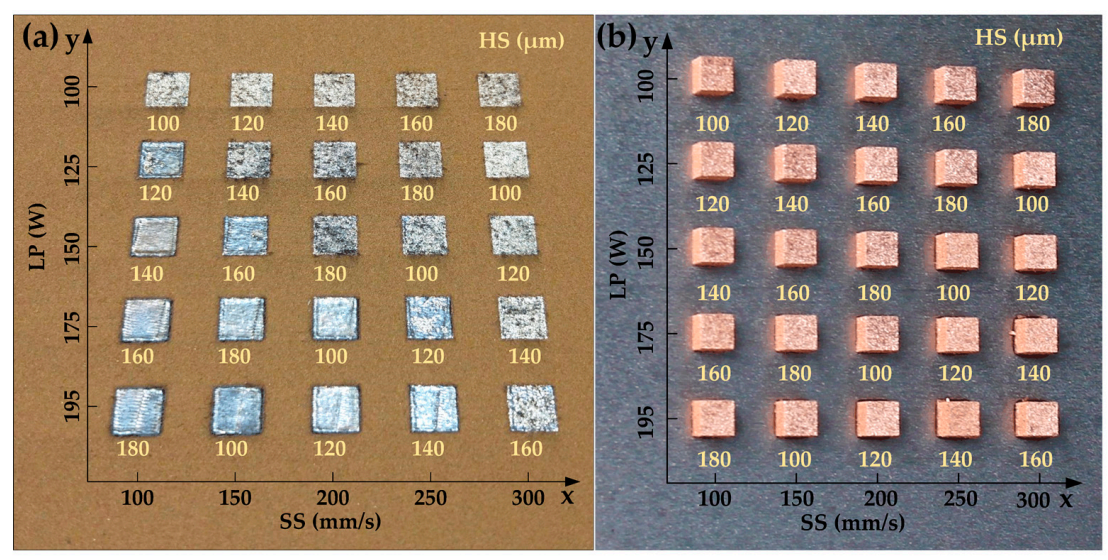

Figure 5. The morphologies of (a) single-layers and (b) specimens with various processing parameters.

The measured results of density and Vickers hardness are elaborated in Table 2. From Table 2, the maximum RD of $93.68 \%$ theoretical density is obtained in the standard order 22, with parametric combinations of LP $=195 \mathrm{~W}, \mathrm{SS}=150 \mathrm{~mm} / \mathrm{s}$ and HS $=100 \mu \mathrm{m}$. Meanwhile, the maximum Vickers hardness of $118 \mathrm{HV} 0.3 / 5$ is acquired corresponding to the standard order 23 , which is significantly higher than the traditional pressure-processed $\mathrm{Cu}-4 \mathrm{Sn}$.

Table 2. Experiment design matrix and results of the Greco-Latin square design experiment.

\begin{tabular}{|c|c|c|c|c|c|c|c|}
\hline \multirow{2}{*}{$\begin{array}{l}\text { Standard } \\
\text { Order }\end{array}$} & \multirow{2}{*}{$\begin{array}{l}\text { Run } \\
\text { Order }\end{array}$} & \multicolumn{3}{|c|}{ Factors } & \multicolumn{3}{|c|}{ Responses } \\
\hline & & LP (W) & $\mathrm{SS}(\mathrm{mm} / \mathrm{s})$ & HS $(\mu \mathrm{m})$ & $\begin{array}{l}\text { Density } \\
\left(\mathrm{g} / \mathrm{cm}^{3}\right)\end{array}$ & RD (\%) & $\begin{array}{c}\text { Vickers Hardness } \\
\text { (HV 0.3/5) }\end{array}$ \\
\hline 1 & 6 & 100 & 100 & 100 & 7.577 & 86.71 & 79 \\
\hline 2 & 5 & 100 & 150 & 120 & 8.282 & 86.61 & 89 \\
\hline 3 & 19 & 100 & 200 & 140 & 7.657 & 87.10 & 82 \\
\hline 4 & 3 & 100 & 250 & 160 & 8.211 & 85.84 & 83 \\
\hline 5 & 1 & 100 & 300 & 180 & 7.717 & 85.04 & 81 \\
\hline 6 & 20 & 125 & 100 & 120 & 7.728 & 89.57 & 95 \\
\hline 7 & 13 & 125 & 150 & 140 & 8.296 & 88.51 & 86 \\
\hline 8 & 15 & 125 & 200 & 160 & 7.991 & 88.85 & 87 \\
\hline 9 & 18 & 125 & 250 & 180 & 8.284 & 87.29 & 92 \\
\hline 10 & 8 & 125 & 300 & 100 & 8.010 & 89.59 & 92 \\
\hline 11 & 24 & 150 & 100 & 140 & 8.000 & 90.09 & 95 \\
\hline 12 & 22 & 150 & 150 & 160 & 8.135 & 89.92 & 98 \\
\hline 13 & 11 & 150 & 200 & 180 & 7.820 & 89.69 & 95 \\
\hline 14 & 23 & 150 & 250 & 100 & 8.213 & 91.12 & 97 \\
\hline 15 & 12 & 150 & 300 & 120 & 7.925 & 91.20 & 98 \\
\hline 16 & 25 & 175 & 100 & 160 & 8.257 & 90.68 & 95 \\
\hline 17 & 10 & 175 & 150 & 180 & 8.244 & 91.03 & 101 \\
\hline 18 & 17 & 175 & 200 & 100 & 7.786 & 92.42 & 102 \\
\hline 19 & 16 & 175 & 250 & 120 & 7.769 & 92.37 & 106 \\
\hline 20 & 4 & 175 & 300 & 140 & 7.943 & 92.22 & 103 \\
\hline 21 & 14 & 195 & 100 & 180 & 8.347 & 92.41 & 100 \\
\hline 22 & 21 & 195 & 150 & 100 & 7.966 & 93.68 & 104 \\
\hline 23 & 2 & 195 & 200 & 120 & 8.128 & 93.04 & 118 \\
\hline 24 & 9 & 195 & 250 & 140 & 8.017 & 92.87 & 104 \\
\hline 25 & 7 & 195 & 300 & 160 & 8.049 & 93.10 & 103 \\
\hline
\end{tabular}


The main effects plots of RD and Vickers hardness are shown in Figures 6 and 7, respectively. It is clear from Figure 6 that the RD mainly depends on the LP and increases significantly as LP increases from 100 to $195 \mathrm{~W}$. In contrast, the SS has few impacts on the RD and its inset illustrates a minor fluctuation at around $90 \%$ with the increase of SS from 100 to $300 \mathrm{~mm} / \mathrm{s}$. The RD has a negative correlation with the HS, which shows a relatively gentle downward tendency with the increase of HS from 100 to $180 \mu \mathrm{m}$. By comparing Figure 6 to Figure 7, the effect of LP on Vickers hardness presents basically the same trends as that on RD. The differences in Figure 7 are that Vickers hardness plots have peak points versus SS and HS, respectively, which means relatively optimal processing parameters of the Vickers hardness (i.e., $\mathrm{SS}=200 \mathrm{~mm} / \mathrm{s}$ and HS $=120 \mu \mathrm{m}$ ). The phenomenon can be explained by the solidification time being decreased as the SS increases, resulting in the formation of a fine crystal microstructure on the surface of specimens, while a further increase of the SS inhibits inverse segregation of the tin element and the generation of the intermetallic compounds from peritectic and eutectic reactions. The effect of HS on Vickers hardness can be attributed to thermal cycling, which has a significant influence on crystal microstructure transformation and element redistribution in the overlapping zone.

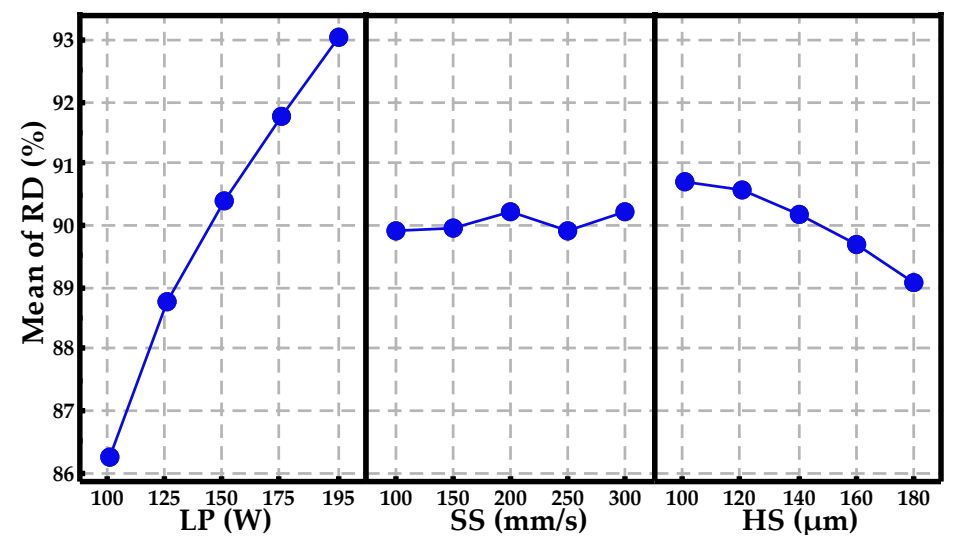

Figure 6. Main effects plot of processing parameters for the mean value of relative density.

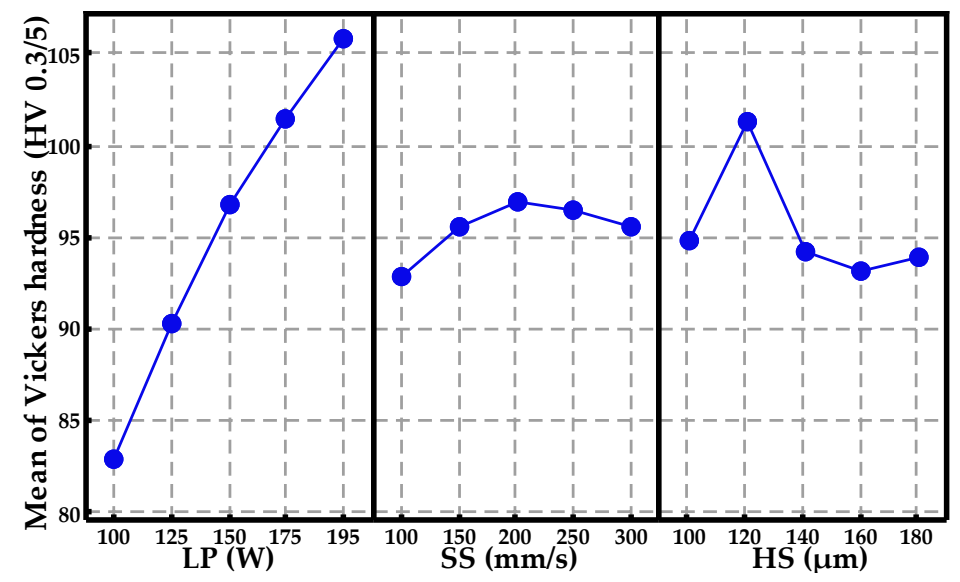

Figure 7. Main effects plot of processing parameters for the mean value of Vickers hardness.

\subsection{Analysis of Variance}

In order to more accurately analyze the statistical influences of various factors, analysis of variance (ANOVA) was carried out using a general linear model based on these RD and Vickers hardness values. There are three impact factors containing LP, SS, HS, and two corresponding responses containing RD and Vickers hardness in ANOVA. Factorial information and results of ANOVA are exhibited in Table 3. 
The $p$-value and F-value were used to judge the significance levels of the factors. A $p$-value less than 0.05 indicates that the influence of this factor is statistically significant. Furthermore, the $p$-value less than 0.01 is termed highly statistically significant [22]. The F-value is the ratio of mean square errors from various factors and experimental errors and when it is below 1 it suggests that the effect of a factor is smaller than that of experimental error; therefore, the factor can be neglected in this experiment [23]. In Table 3, both the F-value (170.59) and $p$-value (0) of the LP in RD ANOVA prove that the LP is the most significant impact factor, followed by the F-value (10.74) and $p$-value (0.001) of the HS. It is noted that the SS has no influence on RD results because the $p$-value (0.586) is greater than 0.25 and the F-value (0.73) is below 1. The Vickers hardness ANOVA maintains a pronounced similarity with RD ANOVA. In the Vickers hardness ANOVA, the LP and the HS convey the conspicuous impacts on the Vickers hardness, and the SS also has no effect on the Vickers hardness.

Table 3. General linear model factors and results of ANOVA.

\begin{tabular}{|c|c|c|c|c|c|}
\hline \multicolumn{6}{|c|}{ Factors Information } \\
\hline Factor & \multicolumn{2}{|c|}{ Type } & Levels & \multicolumn{2}{|c|}{ Values } \\
\hline $\mathrm{LP}(\mathrm{W})$ & \multicolumn{2}{|c|}{ Fixed } & 5 & \multicolumn{2}{|c|}{$100,125,150,175,195$} \\
\hline $\mathrm{SS}(\mathrm{mm} / \mathrm{s})$ & \multicolumn{2}{|c|}{ Fixed } & 5 & \multicolumn{2}{|c|}{$100,150,200,250,300$} \\
\hline $\mathrm{HS}(\mu \mathrm{m})$ & \multicolumn{2}{|c|}{ Fixed } & 5 & \multicolumn{2}{|c|}{$100,120,140,160,180$} \\
\hline \multicolumn{6}{|c|}{ RD ANOVA } \\
\hline Source & DF & Adj SS & Adj MS & F-Value & $p$-Value \\
\hline $\mathrm{LP}(\mathrm{W})$ & 4 & 139.236 & 34.8090 & 170.59 & 0.000 \\
\hline $\mathrm{SS}(\mathrm{mm} / \mathrm{s})$ & 4 & 0.599 & 0.1499 & 0.73 & 0.586 \\
\hline $\mathrm{HS}(\mu \mathrm{m})$ & 4 & 8.767 & 2.1918 & 10.74 & 0.001 \\
\hline Error & 12 & 2.449 & 0.2041 & - & - \\
\hline Total & 24 & 151.051 & - & - & - \\
\hline \multicolumn{6}{|c|}{ Vickers Hardness ANOVA } \\
\hline Source & DF & Adj SS & Adj MS & F-Value & $p$-Value \\
\hline $\mathrm{LP}(\mathrm{W})$ & 4 & 1646.8 & 411.7 & 41.31 & 0.000 \\
\hline $\mathrm{SS}(\mathrm{mm} / \mathrm{s})$ & 4 & 48.8 & 12.2 & 1.22 & 0.351 \\
\hline $\mathrm{HS}(\mu \mathrm{m})$ & 4 & 216.8 & 54.2 & 5.44 & 0.010 \\
\hline Error & 12 & 119.6 & 9.967 & - & - \\
\hline Total & 24 & 2032 & - & - & - \\
\hline
\end{tabular}

Residual plots for RD and Vickers hardness are presented in Figures 8 and 9, which contain the normal probability plot of residuals, residuals versus fitted values, the histogram of the residuals, and residuals versus the order of data, respectively. The points in Figure 8a form a straight line, meaning that the residuals of measured RD values with predicted values are normally distributed. Figure $8 \mathrm{c}$ intuitively shows a normal distribution pattern. A random distribution of residuals in Figure $8 \mathrm{~b}$ suggests that this experimental model tends to yield the random error instead of an outlier. In addition, Figure $8 \mathrm{~d}$ is a plot of all residuals in the order that the experimental results were collected and can be used to identify the non-random error and, here, it displays a beneficial experimental process control based on the SPC control chart standard. However, besides the similarity of normal distribution in Figure 9 , the differences in these plots are concerned. The residual range ( -5 to 5$)$ becomes wider than that ( -0.6 to 0.6$)$ in Figure 8 and individual outliers may be produced, as shown in Figure $9 b, c$, which can be ascribed to the resultant porosity in these specimens, leading to the non-random error. 
(a)

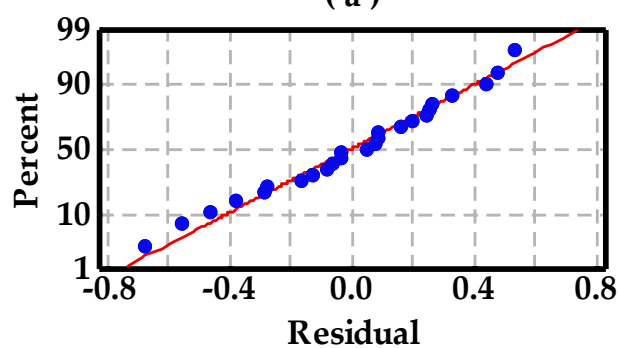

(c)

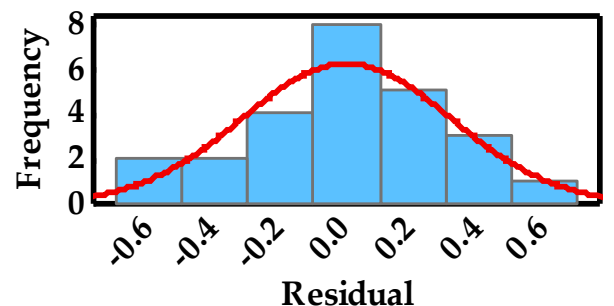

(b)

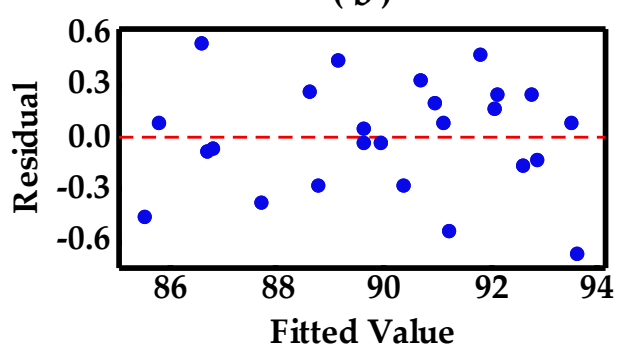

(d)

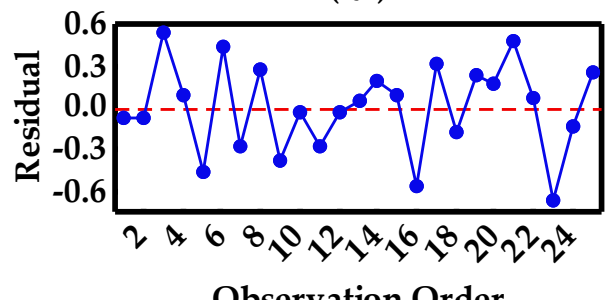

Figure 8. The residual plots for RD: (a) normal probability plot of residuals; (b) residuals versus fitted values; (c) histogram of the residuals; and (d) residuals versus order of data.

( a )

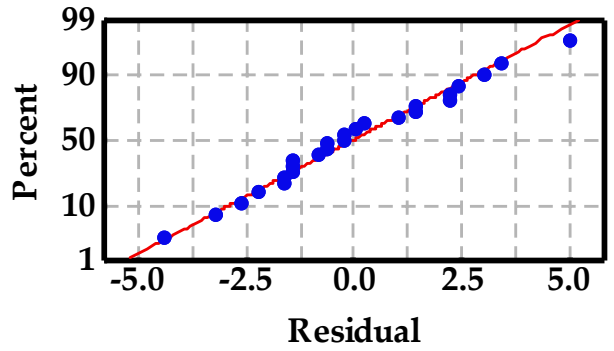

(c)

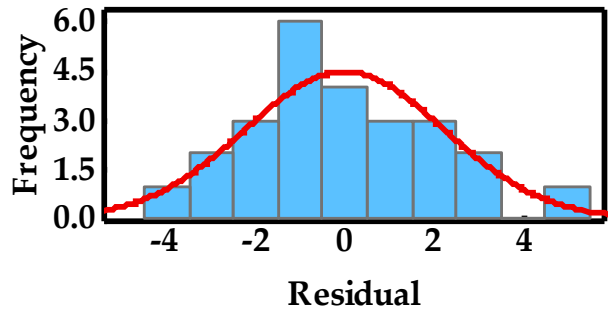

(b)

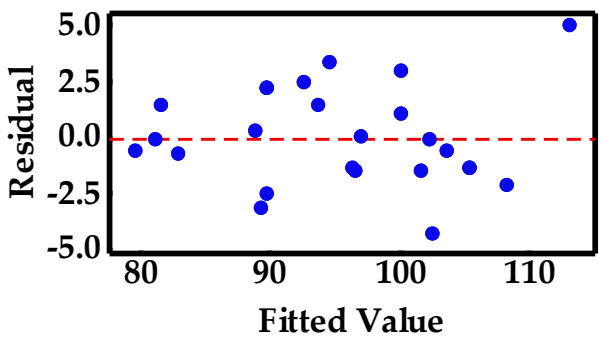

(d)

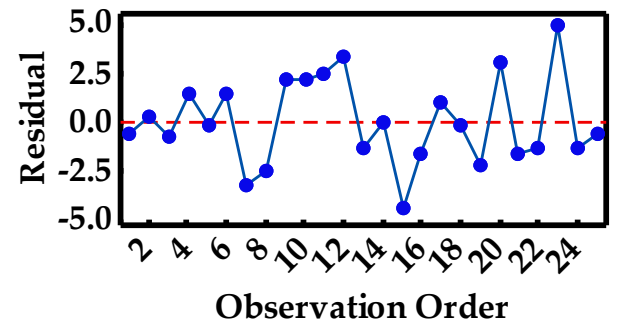

Figure 9. The residual plots for Vickers hardness: (a) normal probability plot of residuals; (b) residuals versus fitted values; (c) histogram of the residuals; and (d) residuals versus order of data.

\subsection{Forming Properties}

Figure 10 shows the surface morphology of a $\mathrm{Cu}-4 \mathrm{Sn}$ specimen with $93.68 \% \mathrm{RD}$ value in the Greco-Latin square design experiment. It is obvious that high surface roughness and discontinuous single tracks can be observed in Figure 10a. A number of defects, such as pores and pits (overlapping defects) are produced, contributing to the relatively low RD. The reasons for these defects can be ascribed to the inadequate laser energy, therefore, resulting in insufficient liquid phase and simultaneously causing a significant shrinkage of the molten pool due to the high surface tension and large viscosity of the liquid phase along with the resultant Marangoni flow. Additionally, it is 
responsible for a non-uniform deposition in the previous layer on account of characteristically rapidly solidifying with a limitation of spreading the molten pool in the overlapping track-track position (as shown in Figure 10b). As a consequence, according to the origins of these defects and above ANOVA, the densities of $\mathrm{Cu}-4 \mathrm{Sn}$ parts manufactured by SLM can be improved further through tailoring a higher energy intensity with a high LP while decreasing SS or narrowing HS are unfavorable methods since they tend to form the unstable molten pool (as shown in Figure 4) and seriously influence the production efficiency in the industrial application. The scaly image on the single tracks can contribute to identifying the scanning direction, as shown by the arrow in Figure 10b.
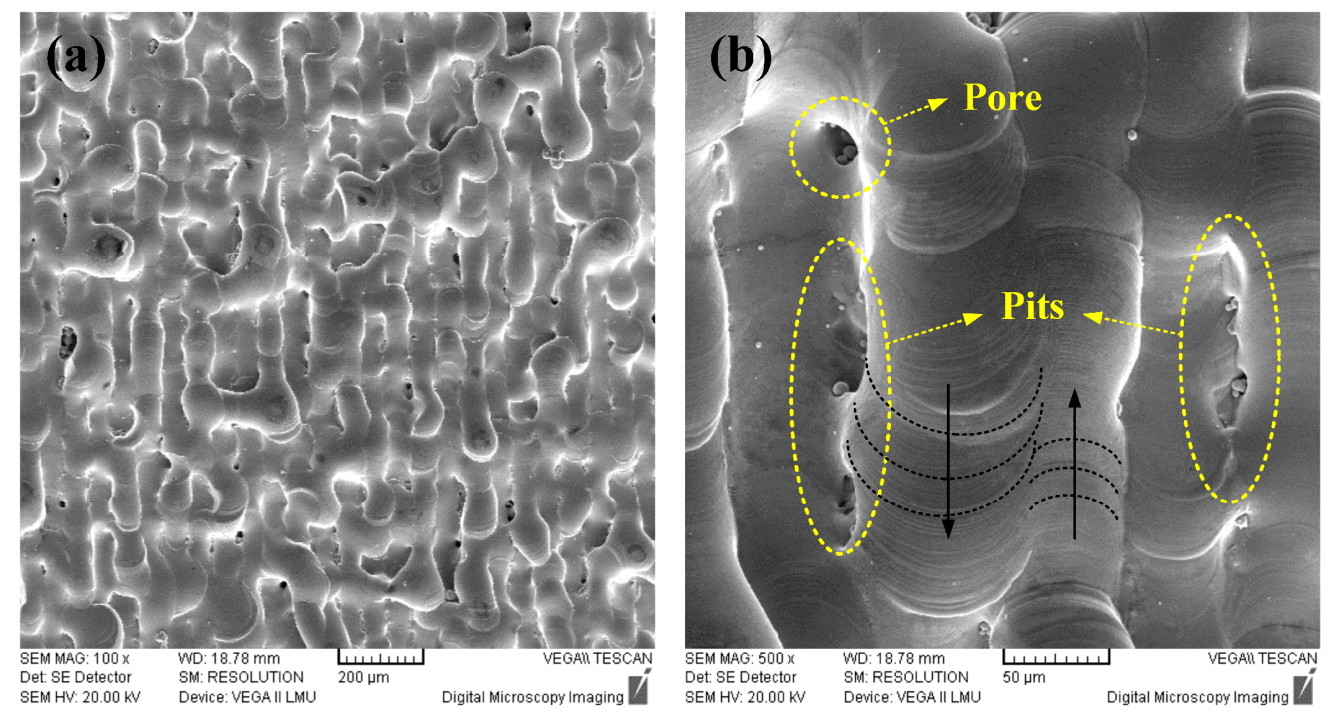

Figure 10. SEM surface morphologies of the Cu-4Sn with the RD 93.68\%: (a) At a low magnification; and (b) At a high magnification.

The tensile specimens of $\mathrm{Cu}-4 \mathrm{Sn}$ were fabricated using relatively optimal parameters set in the above experiments. An attained ultimate tensile strength (UTS) 316-320 MPa is inferior to that of traditional pressure-processed $\mathrm{Cu}-4 \mathrm{Sn}$ (not less than $410 \mathrm{MPa}$ ). Figure 11 shows the fracture surfaces of these tensile samples in order to further understand the fracture mechanism. These samples simultaneously display two features in the Figure 11: step surfaces (Part 1) and dimples (Part 2), thus implying two fracture mechanisms (i.e., brittle cleavage fracture and ductile fracture). The production of two different fracture mechanisms can be ascribed to the segregation of tin in the sample (Figure 11) where point 1 of the step surfaces holds the same tin level as raw materials, while copper content is extremely high on point 2 of the dimples, as presented in Table 4 . Some pores and grooves are also observed in these specimens, which can explain the low UTS. Generally, these defects are crack initiators and influence the overall structural performance during tensile testing. Therefore, defects should be reduced for the further improvement of UTS to meet the needs of applications.

Table 4. The chemical compositions of different point on the fracture surface.

\begin{tabular}{ccc}
\hline \multirow{2}{*}{ Elements } & \multicolumn{2}{c}{ Weight Percentage (wt \%) } \\
\cline { 2 - 3 } & Point $\mathbf{1}$ & Point 2 \\
\hline $\mathrm{Cu}$ & 95.33 & 100 \\
$\mathrm{Sn}$ & 4.67 & 0 \\
Total & 100 & 100 \\
\hline
\end{tabular}



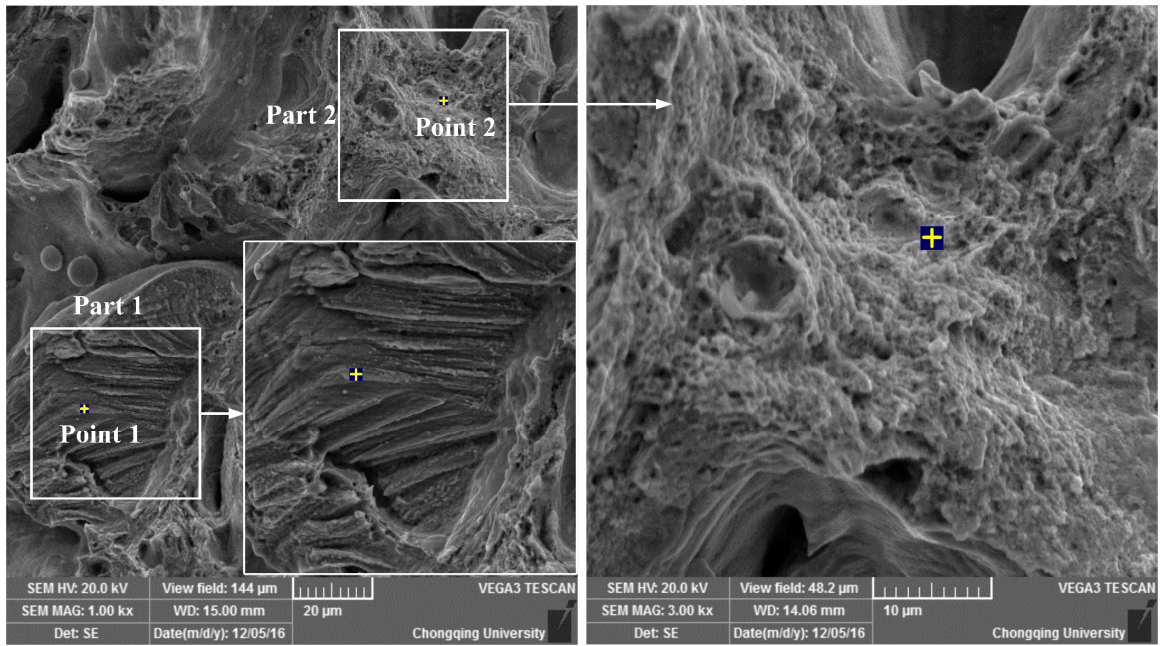

Figure 11. SEM micrograph of fracture surfaces during tensile testing.

\section{Conclusions}

Relatively optimal SLM processing parameters of $\mathrm{Cu}-4 \mathrm{Sn}$ based on the EOSINT M280 equipment were successfully identified and bulk specimens successfully manufactured for the first time using a systematic experimental approach. This proposed experimental approach consists of a single-track experiment and Greco-Latin square design experiment. The obtained conclusions are as follows:

1. The best RD value (93.68\%) was obtained using an optimal SLM processing parametric set of $\mathrm{LP}=195 \mathrm{~W}, \mathrm{SS}=50 \mathrm{~mm} / \mathrm{s}$ and HS $=60 \mu \mathrm{m}$. The best Vickers hardness $(118 \mathrm{HV} 0.3 / 5)$ was also acquired using an SLM processing parametric set (i.e., LP $=195 \mathrm{~W}, \mathrm{SS}=200 \mathrm{~mm} / \mathrm{s}$, and HS $=120 \mu \mathrm{m}$ ).

2. During the experimental process, single-track experiments with different combinations of processing parameters can effectively narrow down selection windows for various parameters. Greco-Latin square design experiments with orthogonal parameter arrays can effectively reduce the number of experiments to acquire optimal processing parameters.

3. The ANOVA permits one to identify statistical influences of processing parameters on RD and Vickers hardness. It is noted that RD and Vickers hardness of $\mathrm{Cu}-4 \mathrm{Sn}$ specimens produced by SLM depend strongly on the LP.

4. The highest tensile strength achieved for $\mathrm{Cu}-4 \mathrm{Sn}$ in SLM is only 316-320 MPa, which is much less than that of traditional pressure-processed $\mathrm{Cu}-4 \mathrm{Sn}$. The main reason for this is due to some internal defects of specimens, such as grooves, pores, and balling. These defects can be inhibited effectively by further improving LP.

Acknowledgments: The authors acknowledge the National High-tech Research and Development Program of China (863 Program: 2015AA042501) for financial support of this work.

Author Contributions: Zhongfa Mao, David Z. Zhang conceived and designed the experiments; Zhongfa Mao and Kaifei Zhang performed the experiments; Zhongfa Mao and Peitang Wei analyzed the data; Zhongfa Mao wrote the paper.

Conflicts of Interest: The authors declare no conflict of interest.

\section{References}

1. Kruth, J.P.; Levy, G.; Klocke, F.; Childs, T.H.C. Consolidation phenomena in laser and powder-bed based layered manufacturing. CIRP Ann. Manuf. Technol. 2007, 56, 730-759. [CrossRef]

2. Yap, C.Y.; Chua, C.K.; Dong, Z.L.; Liu, Z.H.; Zhang, D.Q.; Loh, L.E.; Sing, S.L. Review of selective laser melting: Materials and applications. Appl. Phys. Rev. 2015, 2, 041101. [CrossRef] 
3. Wang, Z.M.; Guan, K.; Gao, M.; Li, X.Y.; Chen, X.F.; Zeng, X.Y. The microstructure and mechanical properties of deposited-in718 by selective laser melting. J. Alloys Compd. 2012, 513, 518-523. [CrossRef]

4. Edwards, P.; Ramulu, M. Fatigue performance evaluation of selective laser melted Ti-6Al-4V. Mater. Sci. Eng. A 2014, 598, 327-337. [CrossRef]

5. Thijs, L.; Verhaeghe, F.; Craeghs, T.; Van Humbeeck, J.; Kruth, J.P. A study of the micro structural evolution during selective laser melting of ti-6al-4v. Acta Mater. 2010, 58, 3303-3312. [CrossRef]

6. Mumtaz, K.A.; Hopkinson, N. Laser melting functionally graded composition of waspaloy ${ }^{\circledR}$ and zirconia powders. J. Mater. Sci. 2007, 42, 7647-7656. [CrossRef]

7. Wang, D.; Yang, Y.; Liu, R.; Xiao, D.; Sun, J. Study on the designing rules and processability of porous structure based on selective laser melting (SLM). J. Mater. Process. Technol. 2013, 213, 1734-1742. [CrossRef]

8. Wang, D.; Wang, Y.M.; Wang, J.H.; Song, C.H.; Yang, Y.Q.; Zhang, Z.M.; Lin, H.; Zhen, Y.Q.; Liao, S.X. Design and fabrication of a precision template for spine surgery using selective laser melting (SLM). Materials 2016, 9, 608. [CrossRef]

9. Caron, R.N. Copper: Alloying. In Reference Module in Materials Science and Materials Engineering; Elsevier: Amsterdam, The Netherlands, 2016.

10. Barik, R.C.; Wharton, J.A.; Wood, R.J.K.; Tan, K.S.; Stokes, K.R. Erosion and erosion-corrosion performance of cast and thermally sprayed nickel-aluminium bronze. Wear 2005, 259, 230-242. [CrossRef]

11. Scudino, S.; Unterdörfer, C.; Prashanth, K.G.; Attar, H.; Ellendt, N.; Uhlenwinkel, V.; Eckert, J. Additive manufacturing of cu-10sn bronze. Mater. Lett. 2015, 156, 202-204. [CrossRef]

12. Gu, D.; Shen, Y. Balling phenomena during direct laser sintering of multi-component cu-based metal powder. J. Alloys Compd. 2007, 432, 163-166. [CrossRef]

13. Gu, D.; Shen, Y.; Lu, Z. Microstructural characteristics and formation mechanism of direct laser-sintered cu-based alloys reinforced with ni particles. Mater. Des. 2009, 30, 2099-2107. [CrossRef]

14. Song, C.H.; Yang, Y.Q.; Liu, Y.; Luo, Z.Y.; Yu, J.K. Study on manufacturing of W-Cu alloy thin wall parts by selective laser melting. Int. J. Adv. Manuf. Technol. 2015, 78, 885-893. [CrossRef]

15. Sing, S.L.; Lam, L.P.; Zhang, D.Q.; Liu, Z.H.; Chua, C.K. Interfacial characterization of slm parts in multi-material processing: Intermetallic phase formation between alsi10mg and c18400 copper alloy. Mater. Charact. 2015, 107, 220-227. [CrossRef]

16. Liu, Z.H.; Zhang, D.Q.; Sing, S.L.; Chua, C.K.; Loh, L.E. Interfacial characterization of slm parts in multi-material processing: Metallurgical diffusion between 3161 stainless steel and c18400 copper alloy. Mater. Charact. 2014, 94, 116-125. [CrossRef]

17. Popovich, A.; Sufiiarov, V.; Polozov, I.; Borisov, E.; Masaylo, D.; Orlov, A. Microstructure and mechanical properties of additive manufactured copper alloy. Mater. Lett. 2016, 179, 38-41. [CrossRef]

18. Wang, X.J.; Zhang, L.C.; Fang, M.H.; Sercombe, T.B. The effect of atmosphere on the structure and properties of a selective laser melted Al-12Si alloy. Mater. Sci. Eng. Struct. Mater. Prop. Microstruct. Process. 2014, 597, 370-375. [CrossRef]

19. Gu, D.; Shen, Y. Effects of processing parameters on consolidation and microstructure of W-Cu components by dmls. J. Alloys Compd. 2009, 473, 107-115. [CrossRef]

20. Yadroitsev, I.; Smurov, I. Selective laser melting technology: From the single laser melted track stability to 3d parts of complex shape. Phys. Procedia 2010, 5, 551-560. [CrossRef]

21. Yadroitsev, I.; Gusarov, A.; Yadroitsava, I.; Smurov, I. Single track formation in selective laser melting of metal powders. J. Mater. Process. Technol. 2010, 210, 1624-1631. [CrossRef]

22. Oehlert, G.W. A First Course in Design and Analysis of Experiments; Kluwer Academic Publishers: New York, NY, USA, 2000; pp. 45-50.

23. Yadroitsev, I.; Yadroitsava, I.; Bertrand, P.; Smurov, I. Factor analysis of selective laser melting process parameters and geometrical characteristics of synthesized single tracks. Rapid Prototyp. J. 2012, 18, 201-208. [CrossRef]

(C) 2017 by the authors. Licensee MDPI, Basel, Switzerland. This article is an open access article distributed under the terms and conditions of the Creative Commons Attribution (CC BY) license (http:/ / creativecommons.org/licenses/by/4.0/). 